\title{
The Correlation between Social Anxiety and Loneliness of Left-Behind Children in Rural China: Effect of Coping Style
}

\author{
Chuanjing Liao',2, Qin Liu ${ }^{3}$, Jinfu Zhang ${ }^{3 *}$ \\ ${ }^{1}$ Southwest Minorities Educational and Psychological Research Center, Southwest University, Chongqing, China \\ ${ }^{2}$ Institute of Psychology and Behavior, Wenzhou University, Wenzhou, China \\ ${ }^{3}$ School of Psychology, Southwest University, Chongqing, China \\ Email: "Zhangif@swu.edu.cn
}

Received 15 May 2014; revised 27 June 2014; accepted 11 July 2014

Copyright (C) 2014 by authors and Scientific Research Publishing Inc.

This work is licensed under the Creative Commons Attribution International License (CC BY).

http://creativecommons.org/licenses/by/4.0/

(c) (i) Open Access

\begin{abstract}
In this study, the relationship between social anxiety, coping style and loneliness amongst left-behind children was investigated. The participants were 773 left-behind children recruited from 8 junior middle schools in rural areas of Zhejiang Province in China who completed the Social Anxiety Scale for Children, Simplified Coping Style Questionnaire and Children's Loneliness Scale. Results show that there was a moderate correlation between social anxiety and loneliness, and these variables had a significant negative relationship with positive coping style and a significant positive relationship with negative coping style. Furthermore, the left-behind children's social anxiety, coping style and loneliness were different within specific demographic groups, such as gender, only child status and different type of parental work. Also negative coping style moderated the association between loneliness and social anxiety, so that children who were more likely to use negative coping strategies showed a stronger relationship between social anxiety and loneliness. Finally, the left-behind children's social anxiety not only directly predicted their loneliness, but also had an indirect effect mediated by their copying style.
\end{abstract}

\section{Keywords}

Social Anxiety, Loneliness, Coping Style, Left-Behind Children

\section{Introduction}

According to the report from the All China Women's Federation [1], there were more than 60,000,000 left-be-

*Corresponding author.

How to cite this paper: Liao, C.J., Liu, Q. and Zhang, J.F. (2014) The Correlation between Social Anxiety and Loneliness of Left-Behind Children in Rural China: Effect of Coping Style. Health, 6, 1714-1723.

http://dx.doi.org/10.4236/health.2014.614204 
hind children in China, who were left by migrant workers who mainly come from remote areas in China especially villages to work in big cities for making more money to improve their living conditions. More and more people pay attention to the education and psychological development of left-behind children among which the problem of their mental health is seriously concerned [2] [3]. According to some researchers, the essence of leftbehind children's psychological development problem is that the long period of parent-child separation results in they can't obtain the continuing care and higher quality parenting, which impacts their psychological development seriously [4] [5]. Moreover, scholars have reported that left-behind children suffer more mental health problems, in which loneliness was the most commonly suffered emotional experience compared with what non left-behind children experience [3] [6].

Loneliness is most commonly defined as an unpleasant feeling arising when an individual perceives a deficiency between the level of social contact one experiences versus desires [7]. There are two theoretical approaches to loneliness - the social need approach and cognitive processing approach [8]. According to the social need theory [9], people have a psychological need to keep in contact with others, and if this contact is not met, people will feel lonely. The theory also emphasizes the affect, or feeling, that loneliness is a response to a relational deficit that gives rise to a yearning for the insufficient relationship. This means that sometimes people may experience loneliness without recognizing the true nature of their distress. On the other hand, scholars within cognitive processing theory suggest that loneliness results from the person subjective perspective in that it arises when one cognitively recognizes a discrepancy between what one wants or hopes for in one's social relationships. As such, cognitive processing theory focuses on how the lonely person perceives and evaluates their social life [10]. Brage stated that loneliness is particularly notable in adolescence compared to other phases of life [11]. Moreover, left-behind children in rural areas lack communication with their families, especially with parents, which can lead them to having a low self-concept [12]. When they perceive their poor interpersonal relationships and feel unsatisfied, loneliness is likely to be the outcome. In summary, it is agreed that the experience of loneliness is unpleasant and distressing; it results from a deficiency in one's social relationships, and is a subjective experience that can only be judged from the subjective perspective of individual.

Social contact is commonly cited as a significant factor determining loneliness in left-behind children in rural areas, and social anxiety also affects loneliness to a large degree [13]. Social anxiety is defined as fears of social situations or of negative evaluation from others [14], and reflected in behaviors such as low self-evaluation, behavior withdrawal and emotional indifference. Eric confirmed that fear of negative social evaluation, as well as avoidance of common or new social situations, are both related to a variety of psychological symptoms [15]. The particular challenges faced by left-behind children often mean that they experience much more social anxiety than non left-behind children [16], which is understood to be related to social self-evaluation and loneliness.

Coping style is the conscious, objective and flexible adjustment behavior of an individual to changes in the social environment [17]. Coping style is one of the important mediating factors that is thought to explain the relationship between individual and psychological stress [18]. Jane, Ireland \& Carol have stated that coping style is an important predictor to poor psychological health among adolescent offenders [19]. There has been much work conducted on copying style in the western literature but rarely researchers apply their theory to examine the left-behind children who lived and grow up under the special family context in rural China. Liao, et al. found that the mental health of left-behind children is seriously worse than the norm, and the mental health of poor children is significantly better than that of the ordinary, and poor children have higher mental resilience than the ordinary group [20]. The mental resilience of poor children plays a role of readjustment and mediation, while the mental resilience of ordinary children plays a role of partial mediation and such a partial mediation effect is higher than that of the ordinary children. This indicates that different economic state of left-behind children may select different coping style from based upon different mental resilience. The study found that for young offenders, rational coping predicted a decrease in overall distress and was found across all symptoms. For juveniles, although detached coping predicted a decrease in overall psychological distress, across symptoms it only predicted social dysfunction. Increased rational coping was also found to predict decreased depression for juveniles. The study highlights differences between young and juvenile offenders regarding coping styles and how this relates to psychological distress. According to Leary's study, individuals with high levels of social anxiety will feel anxious before and after social communication, and this anxiety will consequently affect individual taking which kind of coping style [21]. Susan, Gerben, Jan, Gideon \& Wim found that, coping styles were related to most aspects of social adjustment [22]. The coping styles “seeking social support” and “confrontation” were 
important predictors for positive social adjustment; the coping style "depression" was a predictor for poor adjustment, viz. low social self-esteem and high social anxiety. This indicated that individuals with low social selfesteem and high social anxiety mostly use a repressive coping style such as control one's normal needs in their social adjustment. Many studies, such as that reported by Chen, Ma, \& Daihave found that students with different levels of social anxiety are significantly different in their choice of the coping style [23]. In particular, students with high levels of social anxiety are more likely to use passive ways to solve problems, and their mental health generally poorer. It therefore appears likely that social anxiety will affect the choice of coping style, thereby affecting the loneliness and mental health.

The purpose of this study is to examine the relationship between social anxiety and loneliness among left-behind children in rural areas, and also examine whether, and to what degree, social anxiety affects copying style. It is hypothesized that 1) There will be a significant relationship between social anxiety, coping style and loneliness, 2) There will be a significant difference between different group of left-behind children among social anxiety, coping style and loneliness, 3) The social anxiety will predict the loneliness directly and the coping style will play a moderating and mediating role in social anxiety and loneliness of left-behind children.

\section{Method}

\subsection{Participants}

The left-behind children in this study identified as follows: from 9 to 16 years old, both of whose parents or one of them were moved to city for a work, the time of parents—child separation is at least 6 months. Seven hundred and seventy-three left-behind children in 8 rural schools in Zhejiang Province of China volunteered to take part in this study (mean age $=12.11$ years, standard deviation $=1.01$ years). Because all of the participants in research were under the age of 18, we enhance the ethical considerations highly. The consent from their parents or guardians as well as assent from the left-behind children themselves were obtained, the purpose and method of this study were stated to them. In addition, they were assured that their responses would be confidential and that their identities would not be revealed. In this sample, 392 were males and 381 were females; 166 were single children and 607 were non single children; 541 had two parents away and 232 had one parent away; 180 were in fifth grade, 213 were in sixth grade, 193 were in seventh grade and 187 were in eighth grade.

\subsection{Measures}

\subsubsection{Social Anxiety Scale for Children (SASC)}

The SASC is developed by La Greca, Dandes, Wick \& Stone [24], the Chinese version of SASC is present in Rating Scale for Mental Health by Liu [25]. It's a 10-item self-reported measure of social anxiety including two factors: fearing negative evaluation and social avoidance and distress. Items are rated from strongly disagree (1) to strongly agree (3). Its internal consistency was a coefficient alpha of 0.76 . In this study, the two factors and SASC alpha coefficient was $0.69,0.72$ and 0.75 .

\subsubsection{Children's Loneliness Scale (CLS)}

The CLS, developed by Asher, Hymel, \& Renshaw [26], Ma adapted the CLS into Chinese, and published in the Rating Scale for Mental Health [27]. The CLS want to assess the degree of loneliness and social dissatisfaction of children, and to understand whether the students whom were not accepted by the children is more lonely or not. It is 24-item self-reported measure of loneliness in children. Sixteen items measure loneliness, social adjustment and peer status. The participants rated the items on a 5-point scale ranging from 1 (never) to 5 (often). Scores on the scale range from 16 to 80 with higher scores reflecting greater loneliness or social dissatisfaction. Its internal consistency was a coefficient alpha of 0.90 . For the present study, a Cronbach's alpha coefficient of 0.90 was obtained for the CLS.

\subsubsection{Simplified Coping Style Questionnaire (SCSQ)}

Coping style was assessed through the simplified coping style questionnaire, developed by Xie [28] on the basis of both Chinese and foreign scales [29]. This 20-item questionnaire consists of two sub-scales reflecting coping style-positive coping styles (e.g. talking with people, the annoyance) and negative coping style (e.g. trying to forget the whole thing). Items are rated from never taking (0), to often taking (3). Scores are relatively counted 
on each sub-scale. Its internal consistency is 0.90 . Two sub-scales and whole scale's Cronbach's alpha for this study is $0.79,0.78$ and 0.82 .

\subsection{Procedure}

The 8 schools in the study were randomly determined from the rural primary and secondly schools in Zhejiang Province, China. Self-report measures were administered to students in the classroom environment by researcher. Participation was voluntary and prior to completing the measures, informed consent was obtained from all participants. Students did not place their names on the measures and were assured of the confidentiality of their responses. The students were encouraged to keep their answers confidential and not to talk with classmates about their answers. It took about 20 minutes for students to complete the measures.

\section{Results}

\subsection{Description of All Variables in the Study}

Descriptive statistics and bivariate zero-order correlations for the measured variables are presented in Table 1. The mean score of loneliness of left-behind children is high than that in the study Asher [26] significantly, and the score of social anxiety is significantly high than the city norm observed by $\mathrm{Li}$, Su, Jin, \& The Chinese Collaboration of Children's Anxiety Scale [30], but low than that of social phobia group. The score of negative coping style is higher than that of positive coping style.

\subsection{The Intercorrelations between All Variables in the Study}

Two dimensions of social anxiety (Fearing negative evaluation and social avoidance and distress) are correlated with loneliness; Social anxiety is correlated with positive coping style and negative coping style; coping style is correlated with loneliness (Present in Table 2).

Table 1. Description and difference gender statistics of all variables in the study $(n=773)$.

\begin{tabular}{|c|c|c|c|c|c|c|c|}
\hline \multirow{2}{*}{ Item } & \multirow{2}{*}{ Mean } & \multirow{2}{*}{$S D$} & \multicolumn{2}{|c|}{ Male $(n=392)$} & \multicolumn{2}{|c|}{ Female $(n=381)$} & \multirow{2}{*}{$\begin{array}{l}\text { Comparison of } \\
\text { Mean }(t)\end{array}$} \\
\hline & & & Mean & $S D$ & Mean & $S D$ & \\
\hline Fearing negative evaluation & 5.23 & 2.36 & 5.22 & 2.49 & 5.24 & 2.21 & \\
\hline Social avoidance and distress & 2.68 & 1.72 & 2.58 & 1.64 & 2.78 & 1.78 & \\
\hline Social anxiety & 7.91 & 3.58 & 7.79 & 3.67 & 8.02 & 3.48 & $34.420^{\mathrm{b}},-12.620^{\mathrm{c}}$ \\
\hline Positive coping style & 1.76 & 0.43 & 1.71 & 0.45 & 1.81 & 0.40 & \\
\hline Negative coping style & 1.28 & 0.49 & 1.30 & 0.50 & 1.26 & 0.49 & \\
\hline Loneliness & 33.61 & 10.99 & 33.99 & 11.53 & 33.21 & 10.42 & $2.802^{\mathrm{a}}$ \\
\hline
\end{tabular}

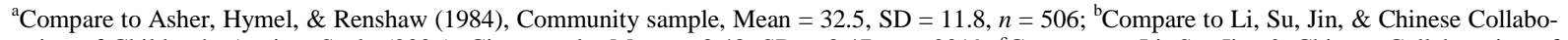
ration of Children's Anxiety Scale (2006), City sample, Mean $=3.48, \mathrm{SD}=3.47, n=2019$; 'Compare to Li, Su, Jin, \& Chinese Collaboration of Children's Anxiety Scale (2006), Social phobia sample, Mean = 9.53, $\mathrm{SD}=5.15, n=32$.

Table 2. Intercorrelations and descriptive statistics of all variables in the study $(n=773)$.

\begin{tabular}{|c|c|c|c|c|c|}
\hline Item & 1 & 2 & 3 & 4 & 5 \\
\hline 1) Fearing negative evaluation & 1 & & & & \\
\hline 2) Social avoidance and distress & $0.530^{* *}$ & 1 & & & \\
\hline 3) Social anxiety & $0.913^{* *}$ & $0.829^{* *}$ & 1 & & \\
\hline 4) Positive coping style & -0.052 & $-0.211^{* *}$ & $-0.136^{* *}$ & 1 & \\
\hline 5) Negative coping style & $0.337^{* *}$ & $0.290^{* *}$ & $0.361^{* *}$ & 0.016 & 1 \\
\hline 6) Loneliness & $0.407^{* *}$ & $0.456^{* *}$ & $0.487^{* *}$ & $-0.382^{* *}$ & $0.418^{* *}$ \\
\hline
\end{tabular}

Note: All correlations are significant at the 0.01 level, ${ }^{* *} p<0.01$. 


\subsection{Group Differences on Social Anxiety, Coping Style and Loneliness in Left-Behind Children}

The results of t-test and F-test found that, female students take more positive coping style than male students; low grade students have higher social anxiety than high grad students; non-single-child students have higher social anxiety than single-child students; two-parents-out left-behind children have higher social avoidance and distress than one-parent-out left-behind children (Presented in Table 3).

\subsection{The Moderating Effect of Left-Behind Children's Coping Style on the Relationship between Social Anxiety and Loneliness}

This study explored whether coping styles of left-behind children influences the degree to which social anxiety impact loneliness, in other words to establish whether coping style plays a moderating role in the relationship between social anxiety and loneliness (Figure 1).

According to the procedure described by Baron\& Kenny [31], the following steps were taken to test for moderation: 1) The social anxiety and coping style variables were centered, 2) an interact terms reflecting "Social anxiety $\times$ Coping style" was created, 3) A regression analysis was conducted with loneliness as the dependent variable. In the process of hierarchal regression analysis, the main effect items of (Social anxiety and Coping style) were entered in the first block, the interaction terms was enbetered in the second block, allowing estimation of whether the, moderating effect is significant or not by examing the increase in prediction of the dependent variable effect ( $\Delta R^{2}$ provided by addition of the interaction item to the model. The results presented in Table 4.

Table 3. Group differences among social anxiety, coping style and loneliness in left-behind children $(n=773)$.

\begin{tabular}{lcccc}
\hline \multicolumn{1}{c}{ Item } & Sex $(t)$ & Grade $(F)$ & Single child $(t)$ & Type of parent out $(t)$ \\
\hline 1) Fearing negative evaluation & -0.145 & $21.099^{* *}$ & $-3.178^{* *}$ & -1.162 \\
2) Social avoidance and distress & -1.667 & $26.132^{* *}$ & $-4.152^{* *}$ & $-2.326^{*}$ \\
3) Social anxiety & -0.895 & $29.841^{* *}$ & $-4.096^{* *}$ & -1.882 \\
4) Positive coping style & $-3.189^{* *}$ & $13.587^{* *}$ & $-2.238^{*}$ & $3.413^{* *}$ \\
5) Negative coping style & 1.165 & $18.340^{* *}$ & -1.063 & $3.325^{* *}$ \\
6) Loneliness & 0.986 & $58.605^{* *}$ & $-2.930^{* *}$ & 0.436 \\
\hline
\end{tabular}

Note: ${ }^{*} p<0.05$.

Table 4. Mediate effect test of coping style between social anxiety and loneliness.

\begin{tabular}{|c|c|c|c|c|c|}
\hline Process & Dependent variable & $\beta$ & $t$ & $\Delta R^{2}$ & $\Delta F$ \\
\hline \multirow[t]{2}{*}{1} & Social anxiety & -1.691 & $-7.146^{* *}$ & 0.228 & $211.382^{* *}$ \\
\hline & Positive coping style & -0.342 & $-11.218^{* *}$ & 0.104 & $110.743^{* *}$ \\
\hline 2 & Social anxiety $\times$ Positive coping style & 1.269 & $5.353^{* *}$ & 0.026 & $28.659^{* *}$ \\
\hline \multirow[t]{2}{*}{1} & Social anxiety & 0.047 & 0.314 & 0.228 & $211.382^{* *}$ \\
\hline & Negative coping style & 0.256 & $7.618^{* *}$ & 0.061 & $61.565^{* *}$ \\
\hline 2 & Social anxiety $\times$ Negative coping style & -0.447 & $-2.998^{* *}$ & 0.009 & $8.986^{* *}$ \\
\hline
\end{tabular}

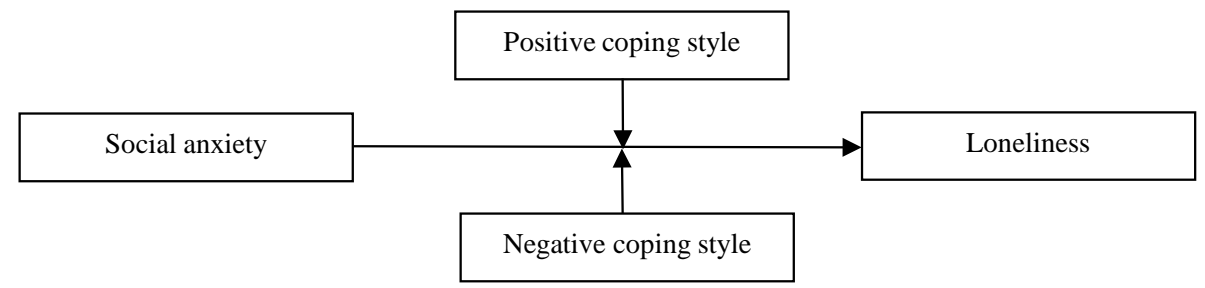

Figure 1. The mediate effect between social anxiety and loneliness. 
Results show that in the hierarchal regression analysis the regression coefficient of social anxiety, positive coping style and negative coping style are all in significant, and the increase in prediction associated with the interaction term was also significant. This means that positive coping style and negative coping style significantly moderate association between social anxiety and loneliness.

In order to describe the moderation effect, we crated groups reflecting the lowest $27 \%$ and highest $27 \%$ of social anxiety score in the sample to reflect low anxiety and high anxiety groups, and then split the low $27 \%$, middle $46 \%$ and top $27 \%$ of the score of positive coping style and negative coping style as low, middle and high coping style group, then created figures describing the moderating effect (Figure 2 and Figure 3).

The two diagram show the moderating effect clearly, which is that when left-behind children take use high levels of positive coping, the association between loneliness and anxiety is small, but it will become larger among those who use low levels of positive coping. When left-behind children take use low and middle levels of negative coping style, the association between loneliness and anxiety is small, but it will become larger among those who use high levels of negative coping.

\subsection{Path Analysis of Social Anxiety, Coping Style and Loneliness among Left-Behind Children}

In order to test the coping style as an intervening variable between social anxiety and loneliness among left-behind children, the fit indices of structural equation model satisfied the requirements and the model fit well. Fit indices: $\chi^{2}=3.997, d f=1, \chi^{2} / d f=3.997, p=0.046, R M S E A=0.062, G F I=0.998, A G F I=0.969, N F I=0.995$, $C F I=0.996, I F I=0.996$. The following model showed that fearing negative evaluation directly predicted loneliness $(\beta=0.18)$ and through an intervening variable (negative coping style) the undirected predicting amount was 0.08 , therefore the total predicting amount was 0.26 ; social avoidance and distress predicted loneliness $(\beta=$ 0.20 ), the undirected amount through negative coping style was 0.05 , and the undirected amount through positive coping style was 0.07, therefore the total prediction amount was 0.32 (see Figure 4).

\section{Discussion}

\subsection{Introduction to the Description of the Results}

The level of loneliness in left-behind children is much higher than the observed in the study Asher [26] indicating that left-behind children feel more lonely than other children. This is because of the special background and developmental environment of left-behind children, most of whom lack parent-child interactions over a long period of time, probably resulting in difficulties in building a stable sense of attachment security. At the same time, they may feel lonelier as a result of living in the relatively closed, poor family environment.

Left-behind children's social anxiety scores were also significantly high than the city norm observed by Li, Su, Jin, \& The Chinese Collaboration of Children's Anxiety Scale [30], at the same time low than that of social phobia group. So, we can see that the social anxiety of left-behind children is higher than ordinary children, but it not reach the level of social anxiety.

Meanwhile, the score of positive coping style is higher than negative coping style, suggesting that left-behind children took more positive coping style than negative coping style.

\subsection{Intercorrelations of All Variables in the Study}

Correlation analysis showed that, among left-behind children, social anxiety is moderately related to loneliness, which is consistent with Peplau, Miceli, \& Morasch [10] and Murray, Robert, \& Adam's [14] studies of this relationship. Mette, Maurice, \& John pointed out that interpersonal stress was significantly correlated with mental pain, somatic symptoms, while social networking can moderate the relationship between interpersonal stress and psychological distress [32]. Individuals with high levels of social anxiety tend to expect negative evaluation by others in interpersonal situations, and are therefore likely to interpret neutral evaluation as negative evaluation, and consequently to worry about this [33]. In life, an individual's loneliness is likely to affect their social behavior. It is often difficult for individuals with high levels of loneliness to establish and maintain good interpersonal relationship, and they feel painful to unsatisfied such relationships [10]. Adolescents with high loneliness often have more anxiety, anger, negative emotions, and fear of negative evaluation, are less optimistic, have poorer social skills, and lower social support, positive mood, emotional stability, extraversion, agreeableness, 


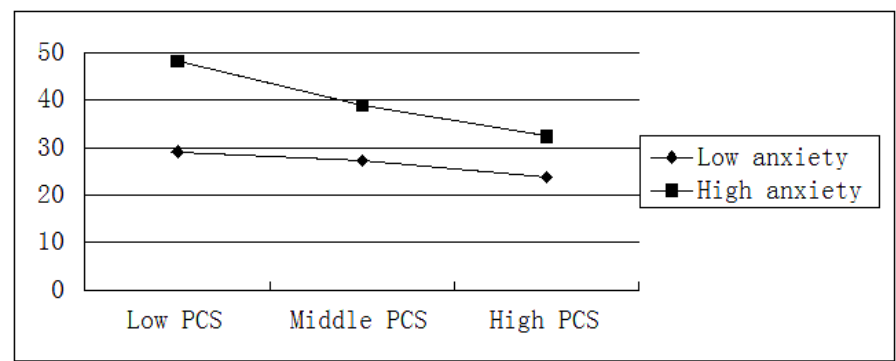

Figure 2. The mediate effect of positive coping style.

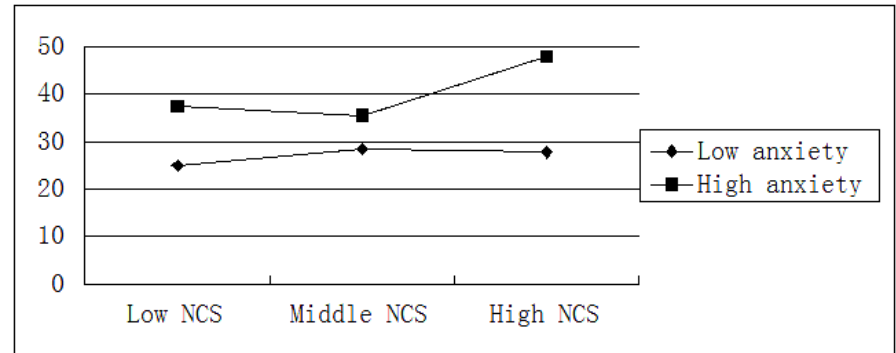

Figure 3. The mediate effect of negative coping style.

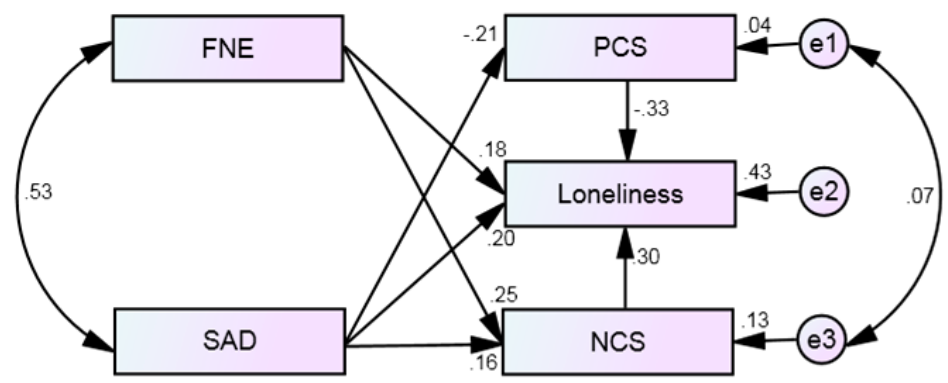

Note: FNE, Fear of negative evaluation; SAD, Social avoidance and distress; PCS, Positive coping style; NCS, Negative coping style.

Figure 4. Structural equation model.

conscientiousness, shyness and social skills [34]. Left-behind children in rural areas are a vulnerable group, and if they are lonely for a long time, there is a risk they will become socially maladjusted and have a poor sense of belonging to their community.

In this study, positive coping style was negatively correlated with social anxiety and loneliness among leftbehind children, while negative coping style was positively correlated with these variables. Ray and Lindop believe that coping style is a kind of behavior used to solve or eliminate problems, and its purpose is to change the environment or the negative emotional experience from environment through the individual's efforts [35]. Everyone has different psychological coping mechanisms and will take certain coping style to ease the pressure from the impact on their mood. Positive coping styles, like problem solving, help seeking, and rationalization, will play an important role to ease the social anxiety and loneliness, while negative coping styles, like fantasy, retreat and remorse, will easily make individual trapped in anxiety and loneliness. Left-behind children who utilize positive coping styles will experience less anxiety and loneliness, whereas the opposite will result from taking negative coping style.

\subsection{Group Differences among Social Anxiety, Coping Style and Loneliness in Left-Behind Children}

The study showed that social anxiety among left-behind children increased significantly with grade increasing, which is consistent with the studies of Wang, \& Chen [16], and Chen, Ma, \& Dai [23]. Low grade children tend 
to overestimate themselves, and their evaluation is often the subjective self-assessment. While with the increase of age, children's self-consciousness will strengthen gradually, and they will pay more attention to their words and deeds and how others may evaluate themselves. This internal focus may cause anxiety. Parents are migrant workers which impact their spiritual growth, especially social intercourse and interpersonal relationship. And the degree of negative impact of both parents outing is higher than one parent outing. Therefore, parents' parenting has positive effect on children's social interaction process. However, the social anxiety and loneliness scores of non-single children were significantly higher than single children, which are contract to experience and has no relevant evidence about this aspect.

There were significant differences in coping style among grades: the scores of high grade students were significantly higher than those of low grade students. The result showed that, as age and education increased, leftbehind children would be more able to solve the problem. Left-behind children with both parents outing take less positive coping style than one parent outing and negative coping style is just the opposite, which states that if lack of family education, especially parents education, it is unfavorable for children to choose appropriate coping styles.

\subsection{The Analysis of Mediate Effect of Left-Behind Children's Coping Style}

In the study of Jinkwan, Ronald, Rapee, \& Hye-Shin, social withdrawal of adolescent resulted in early adulthood will cause social maladjustment, and decreasing loneliness must need better social and emotional adjustment ability [36]. However, coping style is closely related to social adjustment and the coping style or confronting style for seeking social support is important predictors of positive social adjustment, and loneliness, as an aspect of psychological symptoms, will easily produce through the individual's choice of negative coping stylet [22]. Hu, Liu, \& Shenfound that the positive coping style had a significant negative correlation with psychological symptoms among left-behind children [37].

If individuals often use or active in cognitive assimilation the positive coping style such as problem solve, ask for help and rationalization etc., it will be great beneficial to moderate social anxiety, so as to dissolve the loneliness. It can be concluded that the positive coping style and the positive psychological trait can bring positive effect to left-behind children's mental health. But, if someone take negative coping style more frequently, such as fantasy, retreat or remorse, it would be easier to make him or her in a vicious cycle of anxiety and loneliness and cannot extricate oneself. So, when the left-behind children appeared social anxiety, on different levels to take positive or negative coping styles, it will be significant mediate effect on loneliness. And this tell the teachers and parents that if anyone want to help reduce the loneliness of left-behind children, carry out rational education of coping style is necessary and feasible.

\subsection{Path Analysis of Social Anxiety, Coping Style and Loneliness among Left-Behind Children}

The results of constructing the equation model showed that, social anxiety (fearing of negative evaluation and social avoidance and distress) of left-behind children have direct significant predictable effects on loneliness. Children with high social anxiety often lack communication with others, and then cause loneliness and adjustment confusion, and meanwhile may bring a series of psychological problems [23]. Stephen, Kelly, Karen, \& Kelly argues that in early adolescence, close friendship will effectively ease children's social anxiety and loneliness and improve their social self-efficacy [38]. From the two points, social anxiety can predict loneliness.

Further study of the model, social anxiety of left-behind children affected loneliness through coping style. Compared with positive coping style, social anxiety had more indirect prediction effect on loneliness through negative coping style. This study confirmed that the negative coping style is one of the reasons of producing the negative emotion and interpersonal problems. If left-behind children take the negative coping style to deal with social communication problems, they will get deeper lonely experience. By contrast, if they take positive coping style, loneliness caused by social anxiety will be eased. Satisfying social relations are essential to individual's mental health, so how to improve social relationships becomes the focus of society [39]. It is impossible for negative coping style to establish satisfying social relations. Therefore, education should first teach left-behind children stopping or reducing taking negative coping style, and then increase taking positive coping style to improve interpersonal communication, interpersonal adaptability and satisfaction. 


\section{Conclusions}

1) There was a moderate correlation between social anxiety and loneliness and they had a significant negative relation with the positive coping style and a significant positive relation with negative coping style.

2) The left-behind children's social anxiety, coping style and loneliness appear some difference within different groups, such as gender, whether only one child or not and different type of parent's work.

3) The left-behind children's social anxiety has direct prediction effect on their loneliness and an indirect one through copying style, the negative coping style accelerate their loneliness when facing social anxiety.

\section{Acknowledgements}

This study was supported by Youth Found Projects of Humanities and Social Science Research of MOE (Minis-try of Education), P. R. China, 2014: The Psychological Development and Education of Left-behind Children: At the Point of View of Sense of Security (14YJC840017). The authors are grateful to all of the subjects who participated in this study, and especially to Professor N. B. Allen, School of Psychology, The University of Melbourne, and to Dr M. Stephens, Graduate School of Education, The University of Melbourne, Australia.

\section{References}

[1] All-China-Women's Federation (2013) The Report on the Left-Behind Children and Immigrant Children in China. http://news.xinhuanet.com/politics/2013-05/10/c 115720450.htm

[2] Fang, F., Lin, Y.S., Mary, K.G., et al. (2010) Emotional and Behavioral Problem of Chinese Left-Behind Children: A Preliminary Study. Social Psychiatry and Psychiatric Epidemiology, 45, 655-664. http://dx.doi.org/10.1007/s00127-009-0107-4

[3] Liu, Z.F. (2013) Research about the Social Support and Loneliness of Left-Behind Children in Primary School. Education Review, 2, 33-35.

[4] Liu, Z.K., Li, X.Y. and Ge, X.J. (2009) Left Too Early: The Effects of Age at Separation from Parents on Chinese Rural Children's Symptoms of Anxiety and Depression. American Journal of Public Health, 99, 2049-2054. http://dx.doi.org/10.2105/AJPH.2008.150474

[5] Zhao, J.X. and Liu, X. (2010) Rural Left-Home-Children's Depression and Antisocial Behavior: The Protective Role of Daily Pleasure. Psychological Development and Education, 6, 634-640.

[6] Zhao, J.S. and Shen, J.L. (2011) Relationship between Cognitive Appraisal for Left-Home Hassles, Depression and Loneliness in Rural Left-Home-Children. Chinese Journal of Clinical Psychology, 19, 515-517.

[7] Weiss, R.S. (1987) Reflections on the Present State of Loneliness Research. Journal of Social Behavior and Personality, 2, 1-16.

[8] Beverley, T.D. (1999) The Conceptualization and Measurement of Childhood Loneliness. In: Rotenberg, K.J. and Hymels, Eds., Loneliness in Childhood and Adolescence, Cambridge University Press, Cambridge, 11-33.

[9] Bowlby, J. (1973) Attachment and Loss. Vol. 2, Separation: Anxiety and Anger, Basic Books, New York.

[10] Peplau, L.A., Miceli, M. and Morasch, B. (1982) Loneliness and Self-Evaluation. In: Peplau, L.A. and Perlman, D. Eds., Loneliness: A Sourcebook \& Current Theory, Research \& Therapy, Wiley-Interscience, New York, 135-151.

[11] Brage, D., Meredith, W. and Woodward, J. (1993) Correlates of Loneliness among Midwestern Adolescents. Adolescence, 28, 305-312.

[12] Liu, L.J., Sun, X., Zhang, C.L., Wang, Y. and Guo, Q. (2010) A Survey in Rural China of Parent-Absence through Migrant Working: The Impact on Their Children's Self-Concept and Loneliness. BMC Public Health, 10, 32. http://dx.doi.org/10.1186/1471-2458-10-32

[13] Sun, X.J. and Zhou, Z.K. (2007) The Impact of Children’s Peer Relations on Their Loneliness. Psychological Development and Education, 1, 24-29.

[14] Murray, W., Robert, J.C. and Adam, K. (2009) The Correlates and Consequences of Early Appearing Social Anxiety in Young Children. Journal of Anxiety Distress, 23, 965-972. http://dx.doi.org/10.1016/j.janxdis.2009.06.006

[15] Eric, A.S. and Carrie, M.W. (2004) The Relationship of Peer Victimization to Social Anxiety and Loneliness in Adolescent Females. Journal of Adolescence, 27, 351-362. http://dx.doi.org/10.1016/j.adolescence.2004.03.003

[16] Wang, X.D. and Chen, X. (2010) The Comparative Research about the Social Anxiety and Cognitive Biases between the Left-Behind Children and Non-Left-Behind Children. Journal of Sichuan Normal University (Social Science Edition), 37, 57-61.

[17] Joff, P.E. and Bast, B.A. (1978) Coping and Defense in Relation to Accommodation among a Sample of Blind-Man. 
Journal of Never and Mental Disease, 166, 537-552. http://dx.doi.org/10.1097/00005053-197808000-00001

[18] Folk, S. and Lazarus, R.S. (1988) Coping as a Mediator of Emotion. Journal of Personality and Social Psychology, 54, 466-475. http://dx.doi.org/10.1037/0022-3514.54.3.466

[19] Jane, L., Ireland, R.B. and Carol, A.I. (2005) Coping Style and Psychological Health among Adolescent Prisoners: A Study of Young and Juvenile Offenders. Journal of Adolescence, 28, 411-423. http://dx.doi.org/10.1016/j.adolescence.2004.11.002

[20] Liao, C.J., Han, L., Yang, H.Q. and Zhang, J.F. (2014) Mental Health of Staying-at-Home Children in Rural Areas under the Background of Urbanization: From the Angle of Poverty. Journal of Nanjing Agricultural University (Social Science Edition), 14, 21-27.

[21] Leary, M.R. (1986) The Impact of Interactional Impediments on Social Anxiety and Self-Presentation. Journal of Experimental Social Psychology, 22, 122-135. http://dx.doi.org/10.1016/0022-1031(86)90032-6

[22] Susan, A.M., Gerben, S., Jan, O.B., Gideon, J.M. and Wim, H.G.W. (2002) Coping Styles and Locus of Control as Predictors for Psychological Adjustment of Adolescents with a Chronic Illness. Social Science \& Medicine, 54, 14531461. http://dx.doi.org/10.1016/S0277-9536(01)00127-7

[23] Chen, X., Ma, S.J. and Dai, M.L. (2007) A Research on Relationship among Social Anxiety, Coping Style and Mental Health of Countryside Middle School Students. China Journal of Health Psychology, 15, 138-140.

[24] La Greca, A.M., Dandes, S.K., Wick, P. and Stone, W.L. (1988) Development of the Social Anxiety Scale for Children: Reliability and Concurrent Validity. Journal of Clinical Child Psychology, 17, 84-91. http://dx.doi.org/10.1207/s15374424jccp1701_11

[25] Liu, P. (1999) Children’s Loneliness Scale. In: Wang, X.D., Wang, X.L. and Ma, H., Eds., Rating Scale for Mental Health, Chinese Journal of Mental Health, Beijing, 303-305.

[26] Asher, S.R., Hymel, S. and Renshaw, P.D. (1984) Loneliness in Children. Child Development, 55, 1456-1464. http://dx.doi.org/10.2307/1130015

[27] Ma, H. (1999) Children’s Loneliness Scale. In: Wang, X.D., Wang, X.L. and Ma, H., Eds., Rating Scale for Mental Health, Chinese Journal of Mental Health, Beijing, 247-249.

[28] Xie, Y.N. (1998) Preliminary Study to the Reliability and Validity of the Simple Coping Style Scale. Chinese Journal of Clinical Psychology, 6, 114-115.

[29] Zeidner, M. and Endler, N.S. (1996) Handbook of Coping. John Wiley \& Sons, Inc., 107-131.

[30] Li, F., Su, L.Y., Jin, Y. and Chinese Collaboration of Children's Anxiety Scale (2006) The Chinese Urban Norm of Children's Social Anxiety Scale. Chinese Journal of Child Care, 14, 335-337.

[31] Baron, R.M. and Kenny, D.A. (1986) The Moderator-Mediator Variable Distinction in Social Psychological Research: Conceptual, Strategic, and Statistical Considerations. Journal of Personality and Social Psychology, 51, 1173-1182. http://dx.doi.org/10.1037/0022-3514.51.6.1173

[32] Mette, M.A., Maurice, B.M. and Jørn, H. (2010) Interpersonal Stress and Poor Health: The Mediating Role of Loneliness. European Psychologist, 15, 3-11. http://dx.doi.org/10.1027/1016-9040/a000003

[33] Harve, A.G. and Clark, D.M. (2000) Social Anxiety and Self Impression: Cognitive Preparation Enhances the Beneficial Effects of Video Feedback Following a Stressful Social Task. Behavior Research Therapy, 38, 1183. http://dx.doi.org/10.1016/S0005-7967(99)00148-5

[34] John, T.C., Louise, C., Hawkley, J.M., Ernst, M.B., Gary, G., Berntson, B.N., David, S., et al. (2006) Loneliness within a Nomological Net: An Evolutionary Perspective. Journal of Research in Personality, 40, 1054-1085. http://dx.doi.org/10.1016/j.jrp.2005.11.007

[35] Ray, C., Lindop, J. and Gibson, S. (1982) The Concept of Coping. Psychological Medicine, 12, 85-93. http://dx.doi.org/10.1017/S0033291700046729

[36] Jinkwan, K., Ronald, M., Rapee, K.J.O. and Hye-Shin, M. (2008) Retrospective Report of Social Withdrawal during Adolescence and Current Maladjustment in Young Adulthood: Cross-Cultural Comparisons between Australian and South Korean Students. Journal of Adolescence, 31, 543-563. http://dx.doi.org/10.1016/j.adolescence.2007.10.011

[37] Hu, X.Y., Liu, X. and Shen, J.L. (2007) The Affection of Life Events and Coping Styles on Left Children’s Mental Health. Chinese Journal of Clinical Psychology, 15, 501-503.

[38] Stephen, A.E., Kelly, S.F., Karen, L.B. and Kelly, M.T. (2010) Friendships Moderate Psychosocial Maladjustment in Socially Anxious Early Adolescents. Journal of Applied Developmental Psychology, 31, 15-26. http://dx.doi.org/10.1016/j.appdev.2009.05.005

[39] Liesl, M.H. and Eleonora, G. (2006) The Clinical Significance of Loneliness: A Literature Review. Clinical Psychology Review, 26, 695-718. http://dx.doi.org/10.1016/j.cpr.2006.04.002 
Scientific Research Publishing (SCIRP) is one of the largest Open Access journal publishers. It is currently publishing more than 200 open access, online, peer-reviewed journals covering a wide range of academic disciplines. SCIRP serves the worldwide academic communities and contributes to the progress and application of science with its publication.

Other selected journals from SCIRP are listed as below. Submit your manuscript to us via either submit@scirp.org or Online Submission Portal.
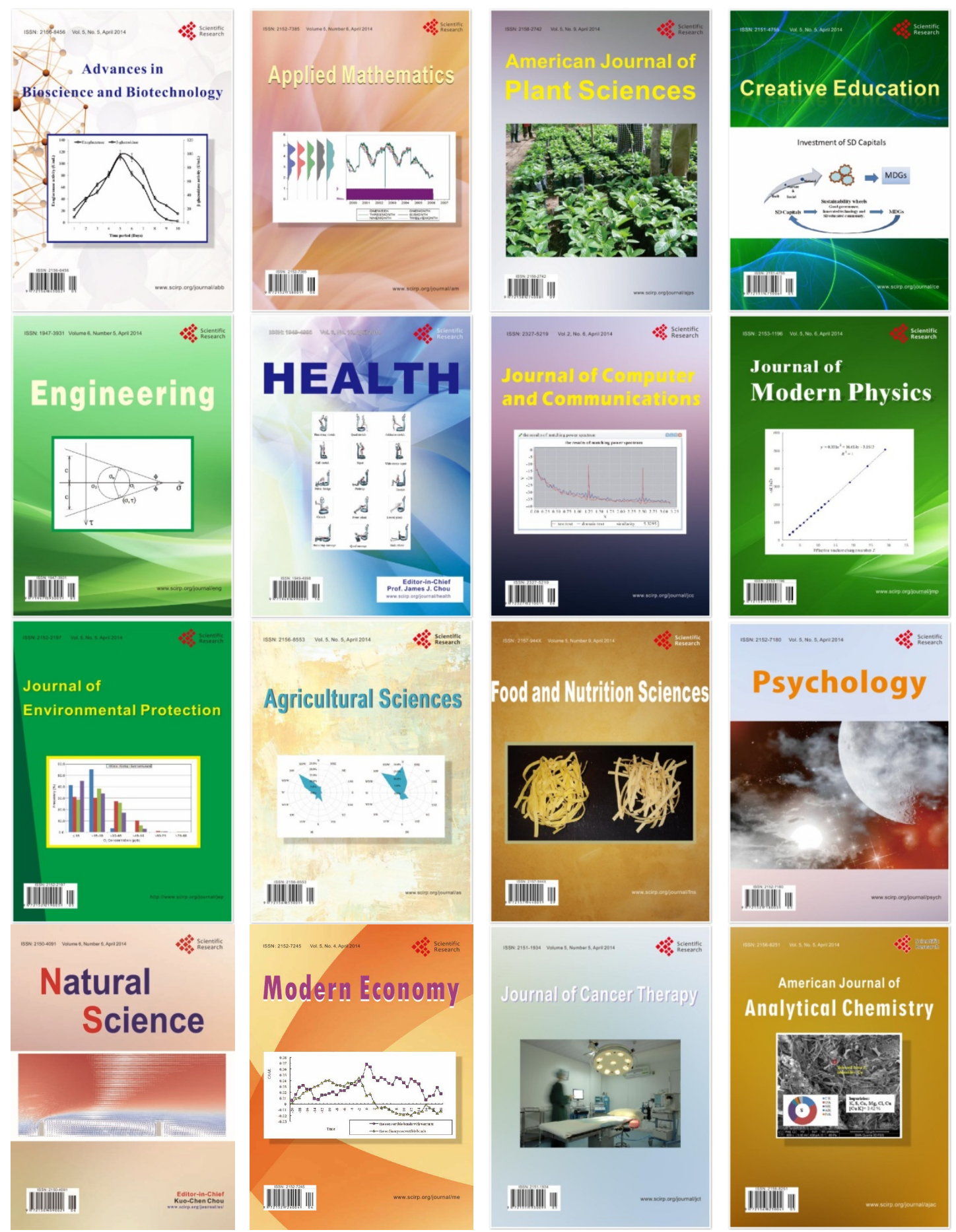